Vol.(8)Issue(1), pp.431-439

DOI: http://dx.doi.org/10.21172/1.81.055

e-ISSN:2278-621X

\title{
DESIGN AND IMPLEMENTATION OF GSM BASED SMART ENERGY METER (SEM) FOR HOME APPLICATIONS
}

\author{
R.Bhavani ${ }^{1}$ and S.Alagammal ${ }^{2}$
}

\begin{abstract}
In conventional method of electricity billing, the responsibility of billing for each consumer is a time consuming job for the distribution grid. Despite this, the consumer can consciously consume extra amount of power than required and still cease from paying the bill. So, nothing can be done to strict the electric power supply. This paper spotlights the design of Smart Energy Meter (SEM) using GSM Technology for domestic consumers. This SEM would insist consumers to consume power during off-peak hours by providing incentives and thereby help to achieve a uniform load curve. This is implemented by time-of-day billing also known as variable billing scheme in which consumers would be charged a higher tariff for power consumption during peak hours. For these reasons it uses Wireless Peak-Hour Timing Update (WPTU) and Wireless Tariff Update (WTU) schemes. In addition, this system also implements Prepaid Billing which would go a extended way in making consumers conscious of the energy they use and be more economical. This device uses ATMEGA 328P Micro Controller for computational purposes, GSM Modem and RF Module for data transfer and updates. The prototype model of this proposed energy meter was developed and was validated with various loads in our laboratory during 19-1-2016 to 25-1-2016(Scale down period as 2 months). It proves, this device is user friendly, make consumers conscious about the amount of energy they spend and help to conserve the already depleting resources. The automation of billing system eliminates labour resources involvement, hence is more accurate.
\end{abstract}

Keywords - Smart Energy Meter (SEM), ATMEGA 328P Micro Controller, Peak Hour, Tariff, Load centre, Consumer End.

\section{INTRODUCTION}

Electricity has become vital in everyday life. It is tough to imagine a world and human life without electricity. But the vitality of electricity has meant that people consume vast amounts of energy unmindfully and carelessly. The world's energy consumption/capita stands at a staggering $2782 \mathrm{KWh}$. At this rate the world's energy resources would get depleted very soon. Already a big chunk of fossil fuel resources got exhausted because of lavish and mindless usage. The present system of energy metering uses electromechanical [1] and somewhere digital energy meter[2] have poor accuracy and lack of configurability and also consumes more time and labour. The conventional electromechanical meters are being replaced by new electronic meters to improve accuracy in meter reading. Still, the Indian power sector faces a serious problem of revenue collection for the actual electric energy supplied owing to energy thefts and network

\footnotetext{
${ }^{1}$ Department of Electrical and Eelectronics Engineering Mepco Schlenk Engineering College, Sivakasi-5, Tamil Nadu,India.

${ }^{2}$ Department of Electrical and Eelectronics Engineering Mepco Schlenk Engineering College, Sivakasi-5, Tamil Nadu,India.
} 
losses. One of the prime reasons is the traditional billing system [3] which is inaccurate many times, slow, costly, and lack in flexibility as well as reliability. Still accuracy cannot be guaranteed as there can be errors in human reading. Also is a post paid scheme makes the consumer to consume more amount of power than required and still refrain from paying the bill and nothing can be done to severe the electric power supply. Even though digital technologies like Power line communication and Zigbee technology are use for meter reading [4] still the problem of deliberately making a false reading can exist (political reasons).

Number of research works has suggested prepaid Automatic meter reading (AMR) system [5-9] provides better customer services, by sending alert of power cuts and consummation updates. Recent developments in this direction seem to provide opportunities in implementing energy efficient metering technologies that are more precise, accurate, error free, etc. Poly phase prepaid energy metering systems have also been proposed and developed based on local prepayment and a card reader [10]. Wireless prepaid energy metering system has been proposed which incorporate RF based system [11]. Digital energy metering system as an alternative for the electromechanical system has been proposed [12]. The above said energy meters which had been implemented are prepaid but it needs Smart card to recharge it. For implementation it needs internet and the computer interface. With the development of GSM infrastructure, which has national wide coverage, can be used to request and retrieve power consumption notification over individual houses. This technology provides energy meter [13-15] with improved billing scheme. The design of proposed meter is directed to eliminate the above said problems by incorporated new features for easy meter reading are capable of being read remotely by the utility company using GSM. The novel time-of-day billing also known as variable billing scheme is introduced would insist consumers to consume power during off-peak hours by providing incentives and thereby help to achieve a uniform load curve. Also Consumers would be charged a higher tariff for power consumption during peak hours. It consists of ATMEGA 328P Micro Controller for computational purposes and a GSM Modem and RF Module for data transfer and updates. This device provides conscious energy consumption and accessibility and readability of usage data to both power companies and consumers alike and a simplified bill payment procedure.

\section{OBJECTIVES OF THE STUDY}

The proposed smart energy meter with advanced prepaid billing system is a device, to make electricity billing user friendly and much more readable to the common man and also provides a plenty of the following advantages.

Energy conservation.

User can recharge number of unit's required (prepaid system).

Lots of time and power saving for electricity department.

Automatic controlling of energy meter.

Non-volatile memory based energy meter storage.

Implements Prepaid Billing which would go a long way in making Consumers conscious about the amount of energy usage and is more economical.

$\square \quad$ Provides automation of the billing system can abolish human involvement hence is more accurate.

It provides a time of-day billing discourages consumers to consume power during peak hours which helps in reduction of energy generation costs.

To make consumers to keep the track of energy usage.

\section{PROPOSED ENERGY METER}




\section{A.Block Diagram}

The block Diagram of the proposed Smart Energy Meter implemented in consumer side is shown in Figure 1. consists of Energy Meter and the Arduino Micro- controller. Energy meter in this system is interfaced with distribution unit through GSM module which operates according to server commands.

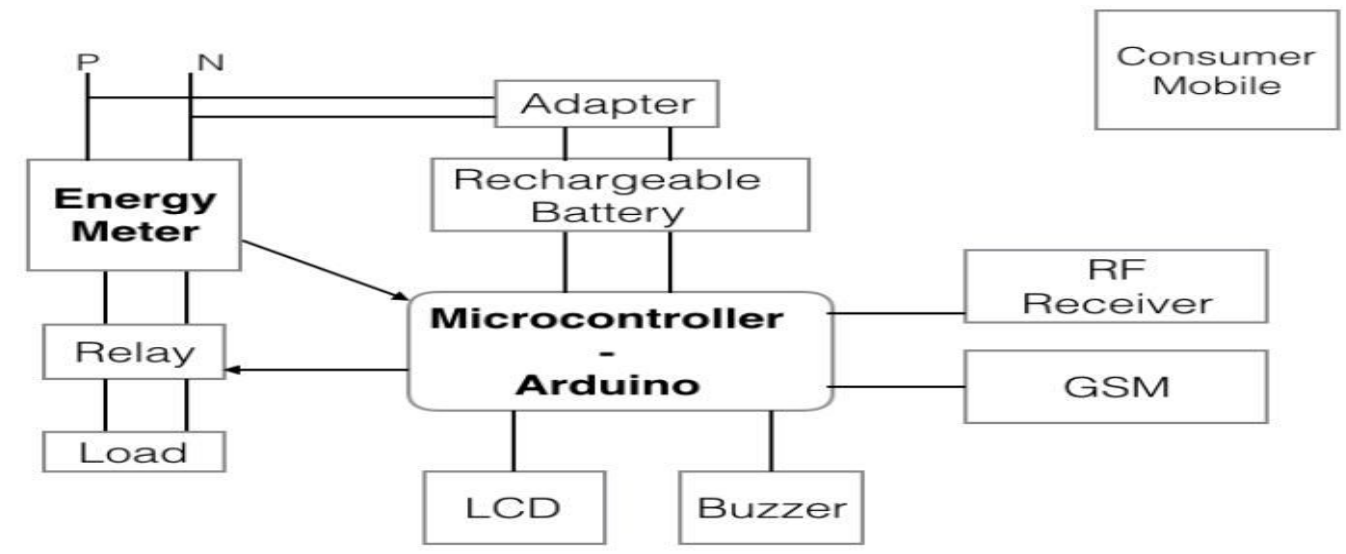

Figure 1. Block Diagram-Consumer End

A new interactive, user friendly graphical user interface web page is developed in load centre side especially for Peak hour Timing, Tariff Update and also consumer recharge is shown in Figure .2.

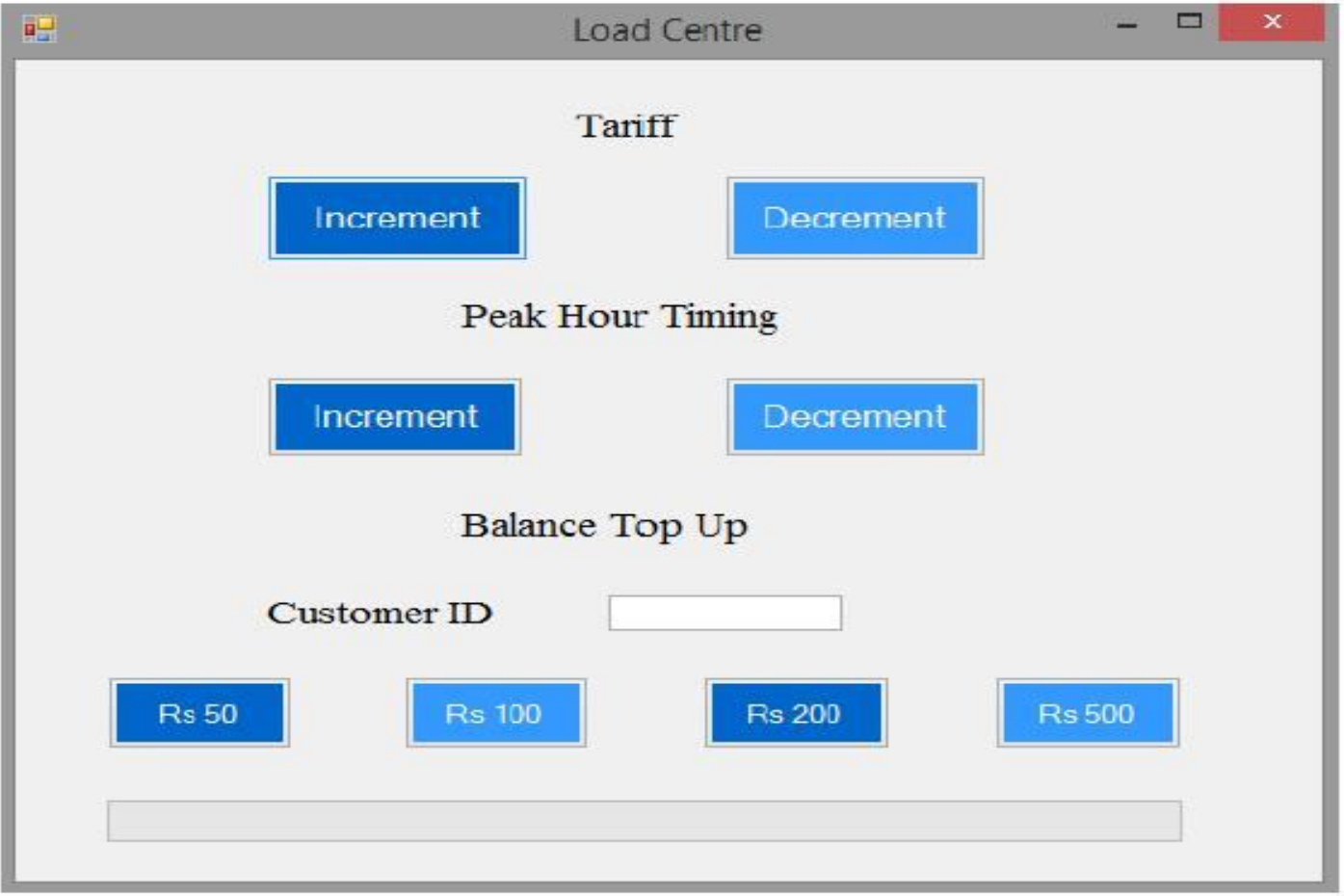


Figure 2. $\quad$ User Interface-Load Centre Side

With proper authentication, users can access the developed web page details from anywhere in the world. The complete monthly usage and due bill is messaged back to the customer after processing these data. Accordingly, the prepaid card is recharged for a certain amount and can be given as input to the Microcontroller. The power from the Electricity Board (EB) is given to the load through the energy meter and a relay.

Energy meter pulses are tapped and given as input to Microcontroller which acts as a data processing and transmission system. It computes energy consumed and decrements the credit balance consequently. The RF Module receives commands from the distribution system regarding tariff and peak hour. The units consumed and balance remaining is indicated by LCD. Whenever the balance becomes zero, the alert signal is given to the consumer through Buzzer. The user can be notified about the detailing usage statistics with the help of the GSM module through SMS. The relay trips the load if bill is not paid for a long duration after allowing some emergency credit as leeway. The power will be supplied again only if the meter is recharged with adequate credit.

\section{B. Algorithm for the proposed system -}

Algorithm for Energy Metering system at consumer's end is shown below.

Start the program.

Set Peak Hour Time, Tarrif Update in the load centre side based on load usage.

Recharge the prepaid account along with consumer ID through GSM.

When the electricity is consumed, decrement recharged amount will start to decrease based on revised Peak Hour and Tariff Rate.

If the balance amount is insufficient, then the user will receive the alert to recharge their prepaid amount.

If the bill is not paid for a long time, disconnect the load from supply and also send message to consumer ID notifying of balance recharge.

\section{Repeat from Step 3.}

B. Flow Chart -

The complete system was described as shown in Figure .3.

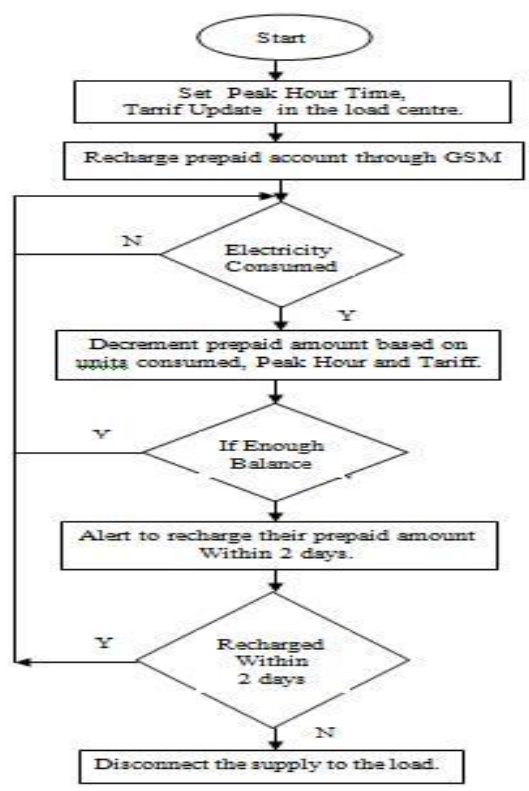


Figure 3.Flow for SEM Prepaid Billing Scheme

\section{HARDWARE IMPLEMENTATION \& RESULTS}

The complete prototype model of GSM based smart energy meter is shown in Figure 4. In this project, an electronic energy meter is used which contains electromechanical counter and metering engine

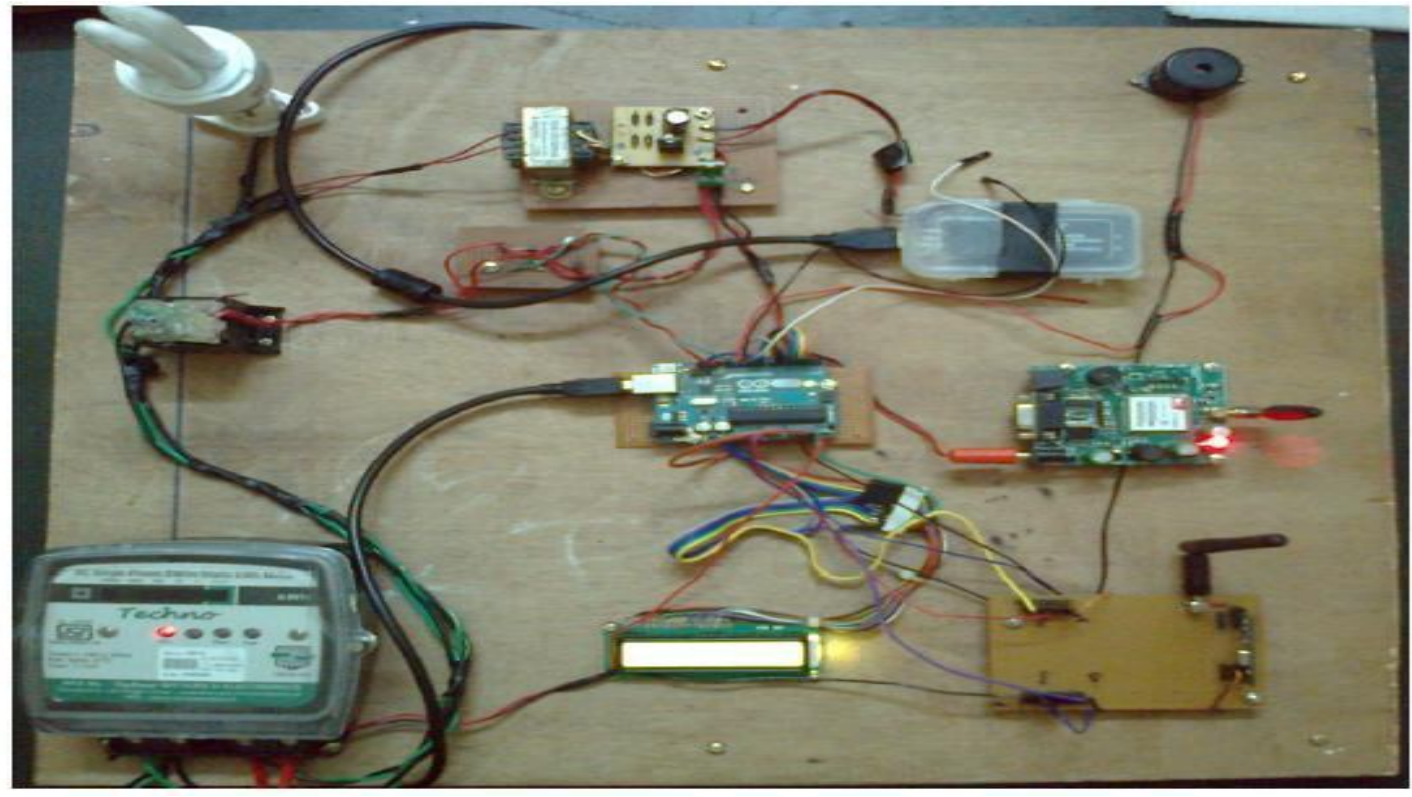

Figure 4.Hardware setup of SEM-Consumer Side.

The metering engine reads the voltage and current inputs from the load has sampled and quantized followed by an ADC section to yield the digitized equivalents of all the inputs. These inputs are then processed using a Digital Signal Processor (DSP) to calculate the various metering parameters. The DSP calculates energy consumption and sends signal to the stepper motor of the electromechanical counter.

In general 3200 impulses denote consumption of 1 unit which is scaled down so that 32 impulses are considered as 1 unit. These pulses are sent to the micro -controller to calculate energy consumption. . Here, the actual units consumed are scaled down so that 32 impulses denote 1 unit, which means that 1/100 th unit is taken as 1 unit. The scales down details are given in Table 1.

Table -1 Scale Down Details

\begin{tabular}{|l|l|l|l|}
\hline $\begin{array}{l}\text { Consumption unit } \\
\text { Slab(bi-monthly) }\end{array}$ & $\begin{array}{l}\text { Energy Charges } \\
\text { (Ps/Unit) }\end{array}$ & $\begin{array}{l}\text { Fixed Charges } \\
\text { (Rs) bi-monthly }\end{array}$ & Scale down units \\
\hline Up to 10 Units & 100 & 5 & $1 / 100^{\text {th }}$ unit $->1$ unit \\
\hline $10-20$ Unites & 150 & 5 & $\begin{array}{l}\text { I Min }->1 \text { Hour } \\
24 \text { Min*7 Days }->1 \text { unit }\end{array}$ \\
\hline
\end{tabular}




\begin{tabular}{|c|c|c|}
\hline 20-40 Units & 200 & 10 \\
\hline Above 40 Units & 300 & 10 \\
\hline
\end{tabular}

The Arduino Uno is a micro-controller board based on the ATmega328Pu microcontroller. It contains everything needed to support the micro-controller; simply connect it to a computer with a USB cable or power it with a AC-to-DC adapter or battery to get started. A $16 \times 2$ LCD is used to display the units consumed and the remaining credit balance and also indicate peak hour. Figure. 5 illustrates snapshot view of a separate module installed at load centre end for two way communication consists of RF Transmitter, PC and data base. The RF transmitter at the load centre end sends commands to the RF receiver at consumer end. It receives usage data from the consumer end sent through GSM. This data is recorded in a database.

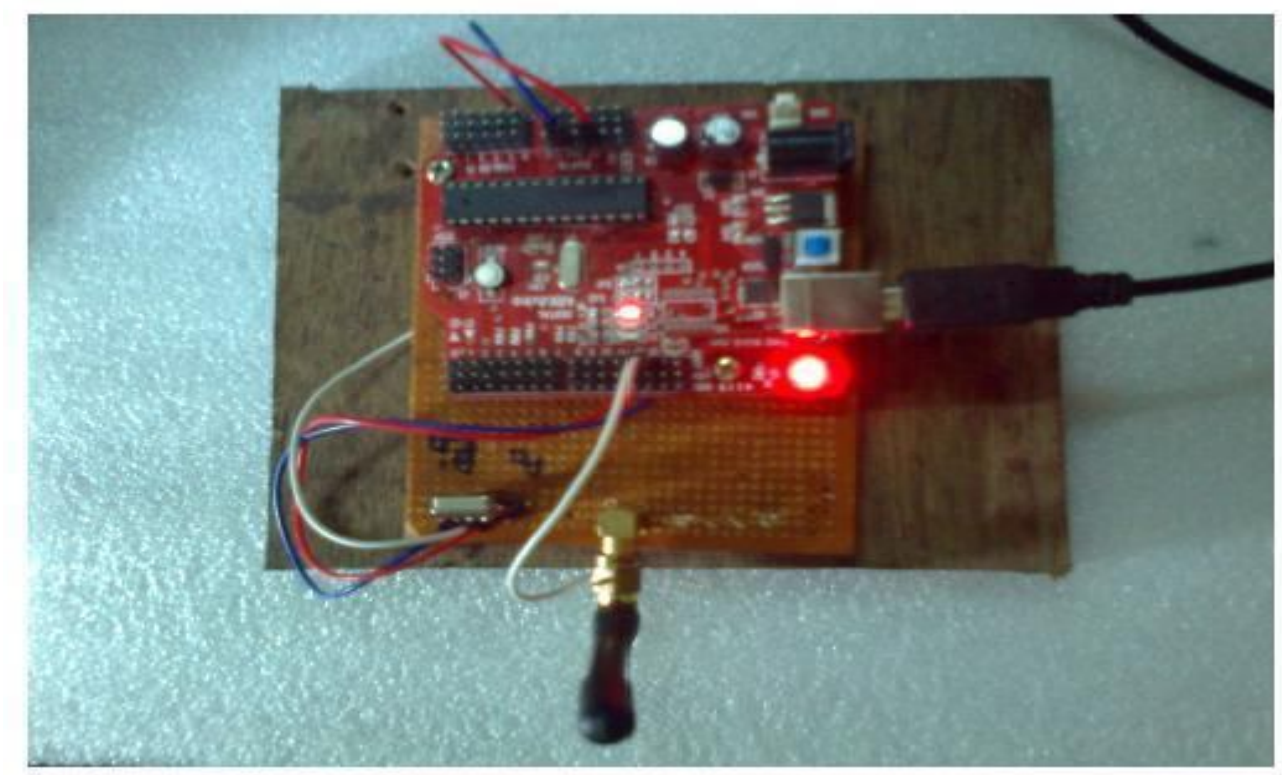

Figure 5.Hardware setup of SEM-Load Centre Side

An RF receiver fitted in the consumer end receives commands from the distribution centre regarding peak hour and tariff. This helps to change the peak hour timing and tariff, whenever necessary, from a remote location. The GSM module in the consumer end sends usage data to the Load Centre and also usage statistics like units consumed, balance remaining, updated peak hour timing and updated tariff to consumer. The updated information in load centre is also send as SMS to every consumer through mobile is shown in Fig 6(a),(b). 


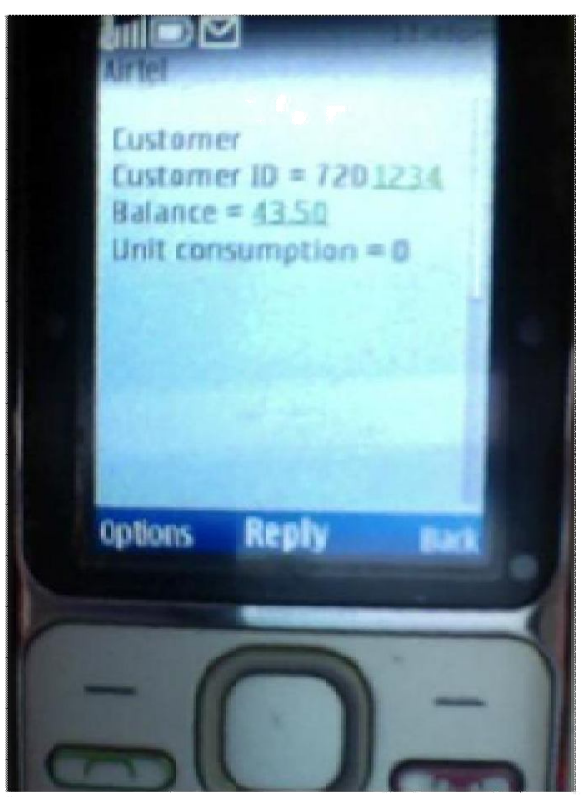

(a)

Figu

Figure 6(a),(b). Message Received at Consumer end

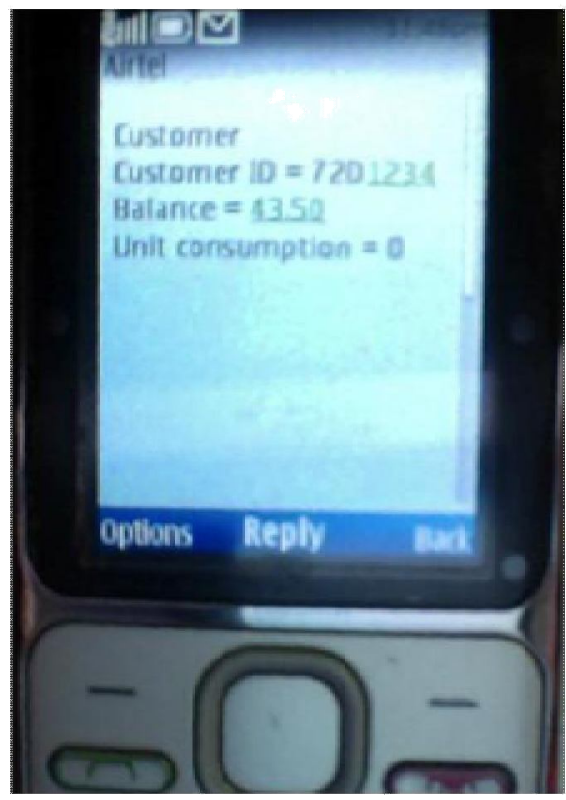

(b)

This GSM Modem-RS232 is built with Dual Band GSM/GPRS engine-SIM900A, works on frequencies 900/ $1800 \mathrm{MHz}$. The Modem is coming with RS232 interface, which allows connecting PC and micro-controller with RS232 interface chip (MAX232). The baud rate is configurable from 9600-115200 through Attention commands (AT). Unlike mobile phones, a GSM modem doesn't have a keypad and display to interact with. It just accepts certain commands through a serial interface and acknowledges for those. These commands are called to instruct the modem to perform its functions. Load is connected to the supply through energy meter and relay. The relay trips the load if the bill is not paid for a long time after allowing some emergency credit as leeway. The Relay used in this project is a 12 V DPDT relay i.e.it needs a 12 $\mathrm{V}$ supply to operate. But the output of the Arduino is only $5 \mathrm{~V}$.

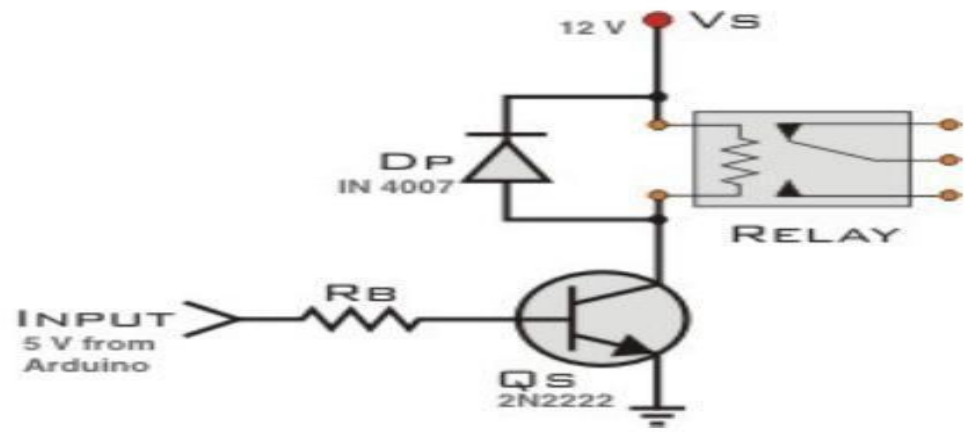

Figure 8.Relay Driver Circuit 
Hence a Relay Driver circuit shown in Figure 7. is needed to operate the relay. A IN 4007 diode is connected across the relay. The $5 \mathrm{~V}$ signal from the Arduino is given as gate signal to the base of the $2 \mathrm{~N} 2222$ transistor. The transistor acts as a switch and when it is closed, the relay operates. The relay trips the load if the bill is not paid for a long time after allowing some emergency credit as leeway. If customer pays the bill, his connection will reconnect. Energy meter sends a SMS alert to energy provider Company gets the information of power load at any time. Experimental tests have been carried out in laboratory with various loads and the energy consumption is measured for two months scaled down one week. During testing, the proposed SEM measurement system was able to correctly perform the monitoring of energy consumption, automation of billing scheme, Sending SMS to consumers about Peak Hour Timing, Number of units consumed and prepaid balance amount

\section{IV.CONCLUSION}

In the proposed SEM using GSM would go a long way in making people conscious of the amount of energy they spend and help to conserve the conventional depleting resources. The automation of billing system eliminates human involvement hence more accurate and reliable. The implementation of time of-day billing can control the usage of electricity on consumer side to avoid wastage of power which helps in reduction of energy generation costs. The introduced Prepaid Billing System minimizes the Electricity theft in a cost effective manner. Automation of meter reading also gives the information of total load used in a house on request at any time as well as to make consumers to keep track of energy usage. It sends a SMS alert to energy provider company whether a person using more than specify limit of load. The use of a web-service developed at load centre has made it possible to overcome the computational complexity of smart meters currently used on the market.

\section{REFERENCES}

[1] A K Shawhney, "Electrical and Electronics Measurements and Instrumentation" by Dhanpat Roy \& Sons, 4th Edition 2007.

[2] Vivek Kumar Sehgal,Nitesh Panda, Nipun Rai Handa, "Electronic Energy Meter with instant billing”, UKSim Fourth European Modelling Symposium on Computer Modelling and Simulation.

[3] Devidas, A.R., Ramesh, M.V. ,'Wireless Smart Grid Design for Monitoring and Optimizing Electric Transmission in India, 2010 Fourth International Conference on Sensor Technologies and Applications (SENSORCOMM)", pp.637-640, 2010.

[4] Kwang-il Hwang, "Fault-tolerant ZigBee-based Automatic Meter Reading Infrastructure", Journal of Information Processing Systems, 5(4), 2009, pp. 221-228.

[5] Md. Mejbaul Haque, Md. Kamal Hossain, Md. Mortuza Ali, Md. Rafiqul Islam Sheikh, "Microcontroller Based Single Phase Digital Prepaid Energy Meter for Improved Metering and Billing System", International Journal of Power Electronics and Drive System (IJPEDS), 1(2), 2011.

[6] O.Homa Kesav, B. Abdul Rahim, "Automated Wireless Meter Reading System for Monitoring and Controlling Power Consumption", International Journal of Recent Technology and Engineering (IJRTE) ISSN: 2277-3878,1(2),2012.

[7] B.O.Omijeh, G.I.Ighalo,"Design of A Robust Prepaid Energy Metering And Billing System",JORIND,10(3),2012.

[8] Syed Khizar Ali Zaidi I, HuraMasroor I, Syed Rehan Ashraf I and Ahmed Hassan, "Design and Implementation of Low Cost Electronic Prepaid Energy Meter", NED University of Engineering and Technology, Karachi, Pakistan, 2010. 
[9] HuraMasroor I, Syed Rehan Ashraf I and Ahmed Hassan, “ Design and Implementation of low cost Electronic Prepaid Energy Meter”, NED University of Engineering and technology, Karachi, Pakistan, 2010.

[10] Ling Zou, Sihong Chu and Biao Guo., "The Design of Prepayment Polyphase Smart Electricity Meter System, International Conference on Intelligent Computing and Integrated Systems (ICISS)", 22(24), 2010 pp. 430432 ,

[11] Richa Shrivastava and Nipun Kumar Mishra, “An Embedded System for Wireless Prepaid Billing of Digital Energy Meter", International Journal of Advances in Electronics Engineering, 2011,pp. 322-324..

[12] M.C. Ndinechi, O.A. Ogungbenro and K.C. Okafor, "Digital Metering System: A Better Alternative for Electromechanical Energy Meter in Nigeria”, International Journal of Academic Research, 3(5), pp. 189-192, 2011.

[13] Jain and Bagree, “ A prepaid meter using mobile communication”, International Journal of Engineering, Science and 164 Technology,3( 3), 2011, pp. 160-166.

[14]. Abhinandan Jain, Dilip Kumar, Jyoti Kedia , "Design and Development of GSM based Energy Meter International Journal of Computer Applications”, (0975 - 888), 47(12), 2012.

[15]. Ashna.k PG Scholar, Electronics \& Communication Dept.,"GSM Based Automatic Energy Meter Reading",IEEE 2013. 